\title{
HOW AND WHY THE LAW HAS FAILED: AN HISTORICAL ANALYSIS OF SERVICES FOR THE RETARDED IN NORTH CAROLINA AND A PRESCRIPTION FOR CHANGE
}

\author{
KaRen Sindelar* \\ I \\ INTRODUCTION
}

The Education for All Handicapped Children Act (EAHCA or the Act) ${ }^{1}$ has resulted in widespread and relatively rapid implementation of a number of educational innovations, such as formulating individualized education programs (IEP's) for handicapped children, and affording parents an "impartial" hearing rather than a school board hearing when they disagree with a district's program. But whether the implementation of these innovations has improved the substantive education offered to handicapped children is debatable. Unfortunately, it seems that the progress school districts have made in complying with the law's many procedural requirements has obscured the lack of substantive progress in many areas of special education. Districts can achieve strict compliance with procedural requirements such as formulating IEP's, ${ }^{2}$ giving parents notice, ${ }^{3}$ and testing children before placement, ${ }^{4}$ without making significant qualitative improvements in the programs offered handicapped children. The Act's substantive requirements-that children receive a "free appropriate public education" 5 in the "least restrictive environment" used to measure compliance. As a result, any educational offering short of total exclusion can be termed "appropriate" and in the "least restrictive environment." Because compliance with these substantive mandates is so difficult to measure and so easily avoided, educational opportunities offered hand-

Copyright $\odot 1985$ by Law and Contemporary Problems

* Attorney for North Carolina Protection and Advocacy System, North Carolina Governor's Advocacy Council for Persons with Disabilities. The author also served as a State Hearing Officer for P.L. 94-142 appeals in 1979 and 1980.

1. Pub. L. No. 94-142, 89 Stat. 773 (1975) (codified at 20 U.S.C. $\S \S 1400-1461$ (1982)).

2. 20 U.S.C. $\$ 1414(\mathrm{a})(5)(1982) ; 34$ C.F.R. $\S 300.342$ (1984).

3. 20 U.S.C. $\S 1415$ (b)(1)(C), (D) (1982); 34 C.F.R. $\S 300.504$ (1984).

4. 20 U.S.C. $\S 1412(5)$ (c) (1982); 34 C.F.R. $\$ 300.531$ (1984).

5. 20 U.S.C. $\S \S 1401(18), 1412(1), 1414(\mathrm{a})(1)(\mathrm{C})(\mathrm{ii})(1982) ; 34$ C.F.R. $\S \S 300.4, .121, .122, .300$ (1984).

6. 20 U.S.C. $\S 1412(5)(B)$ (1982); 34 C.F.R. $\S \S 300.550-.556$ (1984). 
icapped children are influenced far more by such factors as attitudes of key school personnel and fiscal incentives than they are by the Act itself.

This author, a practicing attorney who has advised both school districts and parents over the past five years, believes that policymakers and researchers have spent too much time assessing compliance with easily measurable procedural mandates of the law, and not enough on whether the substantive education offered handicapped children has improved. Policymakers need to analyze specific substantive education practices or areas of need that were considered problems prior to the EAHCA's passage and determine whether implementation of the law has resulted in improvements in those areas. If the Act has not had an impact, the causes for failure should be examined and federal efforts should be targeted at those causes.

This article attempts to identify some causes for the failure of the EAHCA to bring about changes in one area of special education. The author examines a specific problem area that existed prior to the passage of EAHCA - the inferior and segregated education offered to lower functioning retarded children. Both the status of services to these children prior to the Act's passage and current practices are discussed. The author then analyzes how certain factors have operated as barriers to change and have impeded progress in this problem area. In particular, historic practices, state fiscal policies, attitudes of key actors at the local level (including parents) and state and federal monitoring are examined. The author also looks at how some of the same factors have helped promote change in certain school districts. Based on this analysis, suggestions are offered concerning new federal incentive programs and regulatory changes that could bring about greater progress in this area of need.

The description, analysis, and conclusions drawn in this article are based on the author's own casework, observations, and discussions with teachers, parents, and administrators rather than on research or theories concerning institutional change. Although the author's experience has been limited to North Carolina, discussions with advocates in other states and recent court cases $^{7}$ challenging systemic inadequacies in services for the retarded indicate that this problem exists on a nationwide basis, even in states with well-funded special education programs. Also, the primary spokesperson on special education matters for the United States Department of Education has identified continuing unnecessary segregation as a national problem. ${ }^{8}$

This particular problem was selected because it illustrates how factors not

7. See, e.g., Roncker v. Walter, 700 F.2d 1058 (6th Cir.), cert. denied, 104 S. Ct. 196 (1983) (challenge to Ohio's statewide system of educating the moderately retarded in segregated schools upheld in light of least restrictive environment mandate); St. Louis Developmental Disabilities Treatment Center Parents Ass'n v. Mallory, 591 F. Supp. 1416 (W.D. Mo. 1984) (challenge to Missouri's statewide system of educating the severely and profoundly retarded in segregated centers dismissed) [hereinafter cited as St. Louis Parents Assoc.].

8. Speech by Madeleine Will, Assistant Secretary for Special Education and Rehabilitative Service to the 62nd Annual Convention of the Council for Exceptional Children, as reported in Summary and Analysis, 1983-84 Educ. HANDICAPPED L. REP. (CRR) SA:119-20 (Apr. 27, 1984) (states and local education agencies are not complying with the least restrictive environment requirement and 
addressed by the EAHCA can frustrate its implementation. There are numerous other examples of failed implementation that similarly affect large numbers of handicapped children. Each of these problems is unique, with its own history and possible solutions. Factors that have impeded or promoted change in one problem area may be relatively insignificant in another. For example, whereas parental attitudes and pressure have been important in shaping services to retarded children, this factor has been relatively insignificant in a different problem area, the lack of adequate educational services for emotionally disturbed and behaviorally disordered children. For this reason, the author believes that meaningful progress will be made in improving the education of handicapped children only if problem areas are examined individually and solutions are carefully constructed.

\section{II}

\section{Identification of the Problem}

\section{A. Some Typical Cases}

In North Carolina, most students who are more than mildly retarded are offered either inferior educational services and facilities or are segregated for their education, or are given an education that is both segregated and inferior. The number of retarded students involved is substantial. In North

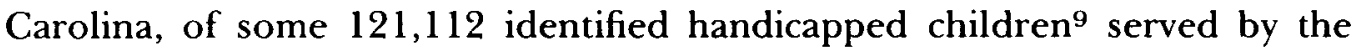
public schools, 4,52910 are identified as moderately retarded, ${ }^{11}$ or having an IQ between 30 and 49 , and $754^{12}$ are identified as severely or profoundly retarded, ${ }^{13}$ or having an IQ below 30 . The following example illustrates both the functioning level of a hypothetical moderately retarded student, as well as the typical program options available to the moderately retarded in North Carolina.

John is a 16-year-old with Down's Syndrome and an IQ of 50. Physically he functions much like a nonhandicapped teenager, except that he is some-

have not developed standards for placement decisions, thus allowing unstructured and subjective decisionmaking).

9. December 1, 1983 Headcount of Children Receiving Special Education in North Carolina, (on file with the Division of Exceptional Children, N.C. Department of Public Instruction) [hereinafter December 1, 1983 Headcount, N.C.].

10. December 1, 1983 Headcount, N.C., supra note 9; October 1, 1983 Headcount for the Education Consolidation and Improvement Act, Chapter I Handicapped (on file with the Division for Exceptional Children, N.C. Department of Public Instruction) [hereinafter October 1, 1983 Headcount, N.C., Chapter I].

11. A mentally retarded student exhibits significantly subaverage general intellectual functioning, along with deficits in adaptive behavior - i.e., the ability to "adapt" to natural and social environmental demands. See 34 C.F.R. \$ 300.5(b)(4) (1984). In North Carolina, the moderately retarded, or trainable mentally handicapped student, is defined as having an IQ in the 30 to 49 range. North Carolina Rules Governing Programs and Services for Children with Special NeEds, § .1509(3) (1984) (issued by the State Department of Public Instruction) [hereinafter cited as Rules].

12. December 1, 1983 Headcount, N.C., supra note 9; October 1, 1983 Headcount, N.C., Chapter I, supra note 10.

13. Rules, supra note 11 , at $\$ .1509(3)$-(4). In addition to having an IQ below 30 , the severely/profoundly retarded student may have a wide variety of handicapping conditions. 
what less coordinated. However, he swims, bowls, plays basketball, and dances, though usually in groups of other retarded teenagers. Although his articulation is poor, he speaks in six or seven word sentences and he is capable of communicating about concrete things and simple abstract issues. Academically he functions at a first to second grade level. He writes his name, identifying information, and simple sentences, and can do simple arithmetic. Vocationally, John helps his father organize goods at his convenience store, does odd jobs around the house, and likes to help his father by identifying tools when his father is fixing small equipment. Socially, John has preteen interests and behaviors. He is interested in girls, sports, and motorcycles. He attends sports events and "hangs out" at the mall with his parents or brother. He interacts with nonhandicapped teenagers at church and in recreation programs. Although it is clear to everyone that he is significantly retarded, John acts appropriately in these social situations. He initiates conversation, responds to overtures from others, follows directions, and generally acts like those around him.

The education offered John varies considerably from district to district in North Carolina. In district A, John would attend a segregated school operated by the system especially for moderately retarded students. The school is old; it was used for black students when the system was segregated. The school serves sixty moderately retarded students from a number of school districts. Students at the segregated school receive physical education, art, and music once a week, less than they would receive in the district's other schools. The children also get one hour less education each day than their nonhandicapped peers; their bus routes are particularly long since they are bussed in from various parts of the district, and beyond. Despite these shortcomings, the principal and parents are proud of the school and consider it "a special place for special people."

District B offers John a cadillac version of the offerings in district A. Thus John would receive physical education, art, and music classes comparable to those given the nonhandicapped, speech therapy according to his needs, and an excellent hands-on vocational training program. The school, though segregated, is very modern. Students receive fewer hours of instruction than the nonhandicapped, however. As in district A, the necessity of transporting the moderately mentally handicapped kids around the district on a few "handicapped buses" leads to longer transportation times and fewer instructional hours. As in district A, John would have no regular contact with the nonhandicapped during the school day.

District C has contracted with a nearby "developmental center" to serve John. The center is part of a system of similar centers that are administered by the State's Department of Human Resources, rather than the state's public school system. The center serves moderately, severely, and profoundly retarded students as well as other students with severe handicaps. It does not offer traditional school services like music and art, except as part of a general recreation therapy program. Nor is there any vocational training in the school 
other than extremely low-level and repetitious training in sorting and ordering.

In district $\mathrm{D}$, John would be placed in an elementary school with eleven other moderately retarded students aged five through twenty-one. None of the students receives art, music, or physical education classes. They are not considered part of the regular school program, and are the only class housed in the old wing of the school, which separates them from the other children. John would have no access to any vocational education since neither vocational courses nor equipment are normally available in an elementary school. However, an "occupational therapist" comes to the class twice a week for thirty minutes to teach students how to separate, sort and order.

Finally, in district E, John would be placed in a high school class for moderately retarded students. Art, music, and physical education are available to him on the same basis as they are to nonhandicapped students. However, the only vocational education offered to John is the opportunity to be bussed to a nearby "sheltered workshop," a segregated work training center for retarded, physically disabled and mentally ill adults.

\section{B. Segregation and Unequal Opportunity: The Common Characteristics}

The above examples typify the range of educational programs available to most moderately, severely, and profoundly retarded students in North Carolina. In forty-nine states, segregated schooling is the norm for the severely and profoundly retarded. ${ }^{14}$ In a number of states it is the dominant service mode for the moderately handicapped as well. Segregated schooling takes many forms. In North Carolina, the predominant mode of service delivery for the severely and profoundly retarded is the segregated developmental center offered by district $\mathrm{C}$ in the example above. Moderately retarded students like John are also placed in developmental centers, but not as frequently. They are generally served directly by school districts, often in segregated schools or in separate buildings, wings, basements or trailers of regular schools. The degree of physical isolation and lack of regular daily contact with the nonhandicapped can be just as great in these settings as in segregated schools.

Services and facilities being equal, it is debatable whether segregation in separate schools denies educational opportunity. Since most retarded students can be offered the intensity of instruction and special services they need in self-contained classes in regular schools with their nonhandicapped peers, segregation is at least a technical violation of the least restrictive environment mandate of the EAHCA. Whether segregation goes beyond this and actually limits educational progress is still in doubt. Since controlled, empirical research concerning the effect of lack of exposure to nonhandicapped peers is virtually nonexistent, ${ }^{15}$ the best available evidence appears to be teacher

14. St. Louis Parents Ass'n, 591 F. Supp. at 1464. (all states but Hawaii have separate education systems for the severely and profoundly retarded).

15. Id. at $1457-64 \& \mathrm{n} .80$ (Plaintiffs' experts maintain that functional and social skills cannot be taught in a separate environment because of insufficient opportunities to intereact with nonhand- 
observations. A sufficient number of school districts in North Carolina have implemented integrated age-appropriate programs for the moderately retarded in North Carolina for some conclusions to be drawn. Educators from these districts have uniformly reported that behavior, social skills, and self-esteem of the moderately retarded have improved as a result of placement with nonhandicapped peers. ${ }^{16}$ If these reports are true, then placement in even the finest segregated facility deprives the moderately retarded student of potential behavioral, social and psychological gains. For the severely and profoundly handicapped, information is sparser; few integrated service models exist for these students in North Carolina or elsewhere. Advocates for these students maintain, however, that they also experience gains from a more integrated placement. ${ }^{17}$

Segregation is not the only problem retarded students face, as shown in the examples above. Whether retarded students are placed in segregated settings or in regular schools, they are commonly offered inferior facilities and are deprived of educational services that the nonhandicapped receive. They receive little effective hands-on vocational education, and fewer enrichment services such as art, music and physical education. Retarded students educated in regular schools are frequently placed in isolated, sometimes inferior sections of the school building. In addition, they are generally placed in ageinappropriate school settings serving students younger than they are.

The deprivations retarded students continue to face have been fully described in St. Louis Developmental Disabilities Treatment Center Parents Association v. Mallory, ${ }^{18}$ the only major challenge of the 1980 's to a statewide segregated system for the retarded. The plaintiffs, five advocacy organizations and thirteen individuals, alleged that Missouri's segregated system of special day schools and facilities for the severely and profoundly retarded violated the EAHCA, section 504 of the Rehabilitation Act of 1973,19 and the United States Constitution. The court ruled against the plaintiffs on all grounds. Most of the state segregated day schools for the severely retarded in Missouri are relatively new, built since 1958 and specially equipped for the handicapped. ${ }^{20}$ The extensive testimony from both sides in the case painted a pic-

icapped and poorer quality of instruction, but admit that research data does not exist to support their positions.).

16. Age-Appropriate High School Programs for the Moderately Retarded, in Pro-Action: A Newsletter from the N.C. Governor's Advocacy Council for Persons with Disabilities, Special Issue (June 1982) [hereinafter cited as N.C. Report on Age-Appropriate High School Programs]. Reports from eight school districts in N.C. that have established integrated age-appropriate programs for high-schoolaged moderately retarded students indicate uniformly positive experience and gains in students' social skills, behavior, and self-esteem.

17. See supra note 15. Other educators, however, claim that functional and social skills do not have to be learned through practice with the nonhandicapped in a regular education environment and, in fact, can be better learned if they are taught through intense instruction in a segregated setting with students then being taken out into the commmunity to practice skills. Id.

18. 591 F. Supp. 1416 (W.D. Mo. 1984).

19. Pub. L. No. 93-112, 87 Stat. 394 (codified as amended at 29 U.S.C. $\$ 794$ (1976)).

20. St. Louis Parents Ass'n, 591 F. Supp. at 1450. Eighty-five percent of the retarded students served in separate special schools in Missouri are in specially designed buildings. 
ture of the continued deprivation suffered by retarded students who are supposedly "integrated" into local schools that was at least as striking as the alleged deprivation experienced by students in segregated settings. For the latter group, the primary discrimination proven was that they were offered only a five-hour school day, rather than the six hours that is standard in Missouri. ${ }^{21}$ But the severely retarded students who had been accepted by their school systems for direct "integrated" service in local schools faced other problems. They were placed in segregated settings such as mobile units or rented buildings away from school grounds. ${ }^{22}$ None of their classes had been located in age-appropriate settings. ${ }^{23}$ Regular education administrators and teachers frequently were unaccommodating. ${ }^{24}$

Statistics that measure the number or the proportion of retarded students who are deprived of an important component of an education program-such as regular integration with the nonhandicapped, comparable enrichment services, or vocational education-do not appear to exist. The problem is difficult to measure, in part because degrees of handicap vary so substantially that it is impossible to say that all retarded students classified within a certain level of retardation would benefit from a particular educational component. Nationally, however, it has been estimated that only 3.3 percent of vocational education students are handicapped, though the percentage of handicapped students in the general school population is at least 12 percent. ${ }^{25}$

This author estimates that in North Carolina, over 90 percent of the severely and profoundly retarded are educated in segregated settings. ${ }^{26}$ Virtually all severely and profoundly retarded students are deprived of enrichment services comparable to those received by the nonhandicapped and of effective, comparable hands-on vocational education. The educational offerings for the moderately retarded are more varied, as the examples offered above show. The author estimates approximately 40 percent of moderately retarded students receive an education in a segregated school or in an iso-

21. Id. at $1468 \mathrm{n} .88$. The denial of a full school day was the only deprivation the court indicated it would remedy, but plaintiffs declined as they were seeking a change in placement from special schools to local schools, not an increase in hours of education in the special schools.

22. Id. at 1451 n.73.

23. Id. at 1454 n.76.

24. $I d$.

25. Vocational Education Data System Statistics, compiled annually by the National Center for Education Statistics (NCES), U.S. Dep't of Educ. (unpublished data collected on a yearly basis through school year 1982-83, available on request from Mr. Arthur Podolsley, NCES) [hereinafter cited as Vocational Education Data Systems Study]. The last year in which statistics concerning handicapped participation were collected was 1980-81; the 3.3 percent figure is from that year.

26. The N.C. Department of Public Instruction reports that for $1983-84,550$ children aged 5 through 17 served in the special developmental day centers were subsidized with special legislative funding. The state does not keep statistics identifying the handicaps of these children, but most are severely and profoundly retarded. Memo to Karen Sindelar from Carolyn Perry, Division of Exceptional Children (Sept. 6, 1984). The total number of 6 to 17-year-old severely and profoundly handicapped school students both in and out of developmental centers was 663. December 1,1983 Headcount, N.C., supra note 9; October 1, 1983 Headcount, N.C. Chapter I, supra note 10. From the author's observation, most of the severely and profoundly retarded students who are served directly by school systems rather than in developmental centers are also placed in segregated settings. 
lated building, trailer, wing, or basement of a regular school. ${ }^{27}$ Of those students integrated into regular schools, approximately 90 percent of retarded students age 12 and above are placed in age-inappropriate settings ${ }^{28}$ and approximately 90 percent are denied a hands-on vocational program comparable in intensity and effectiveness to that offered the nonhandicapped. ${ }^{29}$ Approximately 60 percent of all school-age retarded students are denied enrichment activities such as physical education, music, and art equivalent to those the nonhandicapped receive. ${ }^{30}$ Overall, younger retarded students fare better than older retarded students since placement in elementary schools is age-appropriate for them and since they are not as much in need of vocational education as the older students. However, both young and old students are equally deprived of enrichment activities and speech therapy. In the case of John, the hypothetical moderately retarded student described previously, fewer than ten of North Carolina's 142 school districts would offer him an education in an integrated setting with age-appropriate peers, and vocational and enrichment opportunities comparable to those received by the nonhandicapped.

\section{III}

\section{Causes of the Segregated and Inadequate System}

A combination of factors has contributed to the segregated and inadequate educational opportunities offered the retarded in North Carolina. These factors include: the existence of a segregated service system prior to the passage of the EAHCA and the perpetuation of this system through the state's fiscal policies; beliefs of poorly-educated school district personnel and parents that the retarded must be protected and that they are incapable of benefiting from occupational and enrichment courses available to the nonhandicapped; lack of leadership by the state; and the rigid, unaccommodating response of the state's vocational education system to the needs of handicapped students. These factors will be explored more fully below.

27. An incomplete survey by the N.C. Department of Public Instruction showed that 15 school districts maintain totally segregated facilities for the moderately retarded. Letter to Page McCullough from LaVerne Buchanan, Division for Exceptional Children (June 29, 1984) (on file with the N.C. Governor's Advocacy Council for Persons with Disabilities). Most of these facilities serve children from at least two school districts, and sometimes more, so it can be estimated that between 30 and 45 districts of 142 districts in North Carolina serve their moderately retarded children in totally separate schools. Of the remaining districts, a significant number use isolated areas-basements, trailers, and adjacent buildings-to serve the moderately retarded.

28. N.C. Report on Age-Appropriate High School Programs, supra note 16. An incomplete survey of N.C. school districts showed that eight of 142 had age-appropriate high school programs.

29. Vocational Education Data System Study, supra note 25. From the author's observation, the few handicapped students who are afforded comparable vocational education generally have milder handicaps, such as learning disabilities or mild mental retardation. The moderately and severely handicapped are either deprived of vocational education altogether, or are given special vocational instruction which is less effective than that offered the nonhandicapped, particularly because of the lack of access to vocational equipment and supplies available to nonhandicapped students in high schools.

30. This estimate is based on the author's observation and reports from parents around the state. 


\section{A. Fiscal Policies and Continued Service Outside the Schools for the Severely Retarded.}

In North Carolina, fiscal incentives and attitudes concerning the desirability of segregating the retarded have reinforced and continued a system of educating many of the severely and profoundly retarded outside the public schools. Before the passage of the EAHCA, noninstitutionalized severely and profoundly retarded children were not considered educable. Many, however, received day services in separate "developmental" day centers funded and administered by the State Department of Human Resources. The moderately retarded, in comparison, have been educated in increasing numbers in the public schools since 1957. The state, in 1957, established a special funding system to reimburse local districts for the hiring of special teachers for the moderately retarded at a teacher-pupil ratio established by the state. ${ }^{31}$ Services to the moderately retarded were, of course, discretionary. In districts that did not choose to apply to the state for funds, the moderately retarded were served in the developmental centers along with the more severely retarded.

When the EAHCA was passed, there was resistance to the possibility of closing the developmental centers. For a few years they continued to receive a substantial subsidy from the Department of Human Resources for the school-age children they served. With this subsidy they could contract with local school districts to serve the severely and profoundly retarded for less than it cost districts to serve such students themselves. For a number of reasons, most districts agreed to such contracts for the severely retarded without question despite the EAHCA's mandate for service in the least restrictive environment.

First, the Act's mandate for services in the least restrictive environment was as ambiguous as its requirement for appropriate services. There was no prohibition against serving children in separate schools; in fact, such schools were specifically mentioned in the EAHCA. ${ }^{32}$ Neither the Act nor the regulations implementing it included any presumption that certain categories of handicapped children could generally be served in regular schools as opposed to separate schools which would have guided states and local districts in their interpretation of least restrictive environment. Thus, like most decisions made under the Act, the determination of a child's placement became a function of what service and placement options were already available in a district, rather than what current research or demonstration projects showed about

31. See Law of June 12, 1957, ch. 1369, 1957 N.C. Sess. Laws 1551.

32. 20 U.S.C. $\$ 1412(5)$ (B) (1982). The section states that states must have "procedures to assure that, to the maximum extent appropriate, handicapped children, including children in public or private institutions or other care facilities, are educated with children who are not handicapped, and that special classes, separate schooling, or other removal of handicapped children from the regular education environment occurs only when the nature or severity of the handicap is such that education in regular classes with the use of supplementary aids and services cannot be achieved satisfactorily . . . ." By referring to separate schooling, institutions, and other care facilities, the Act clearly assumes the continued existence of these alternatives. See St. Louis Parents Ass'n, 591 F. Supp. at 1442-43. 
the benefits of integration and normalization. The most prevalent and least expensive placement option that existed for the severely handicapped was the developmental center.

Second, in the initial years of the Act's implementation there was very little support for increased integration. Teachers in school systems had had no experience teaching the severely retarded and public school administrators knew nothing about educational possibilities for such students. Directors and personnel of developmental day centers who had been the primary service providers before the passage of the Act believed that they alone had the desire and the skills to teach the severely retarded. Parents generally agreed, since the developmental day centers were a known quantity that had successfully offered their children services in the past. Also, the State Department of Public Instruction neither trained local administrators about the benefits of educating the severely handicapped in the least restrictive environment nor discouraged the development day school placements through its monitoring activities. Since there were no attempts to reeducate service providers, financial subsidies favored developmental day placement, and there were no agents pushing for change in the existing system, the passage of the Act had little immediate impact on the segregation of severely and profoundly retarded children.

The situation for the moderately retarded was somewhat different. Since the moderately handicapped had been served in increasing numbers in the public schools in the 1950's and 1960's, ${ }^{33}$ the idea of serving these students was not as foreign to the schools as was the concept of serving the severely handicapped. In addition, the state fully subsidized services for the moderately handicapped by providing teachers on the basis of the number of moderately retarded students a district served. This subsidy was not sufficient to provide enough teachers for the severely retarded. Thus, both attitudes and funding incentives favored direct service to the moderately retarded by the public schools. Passage of the EAHCA merely confirmed the right to an education in the public schools that most of the moderately retarded were already enjoying in North Carolina.

For the severely retarded, a situation had developed by 1979 that was ripe for change. Although most school districts had entered into contracts with nearby developmental centers to serve the severely retarded, the Department of Human Resources had, by this time, withdrawn its financial support for these school-age children in light of the public schools' legal responsibilities. Without the financial subsidy from the state, the developmental centers were increasing their charges to local districts. As a result, many districts were looking into the feasibility of serving the severely retarded directly in the

33. Number of Exceptional Children Served by Special Teachers, North Carolina Public Schools, Statistical Summary by School Year (Undated chart compiled by N.C. Department of Public Instruction) (on file with the N.C. Governor's Advocacy Council for Persons with Disabilities). In school year 1957-58 the state started funding special teachers for the moderately retarded. In that year, 391 students were served. The number increased substantially each year, with 2,049 moderately retarded students being served in 1968-69, 3,228 in 1971-72, and 4,424 in 1975-76. 
public schools in hopes of decreasing costs. The actions that followed illustrate the important role that institutional interests seeking self-preservation play in impeding change. The developmental centers looked first to the State Department of Public Instruction for a direct subsidy. When the State Department refused to subsidize the centers, they approached the legislature through an organized association. Although the State Department of Public Instruction did not favor legislative funding, it did not fight the request. No opposition was voiced by any advocacy group, including the Association for Retarded Citizens. Thus, in 1979, the legislature initiated a direct subsidy to the centers which continues to date. ${ }^{34}$ Although the subsidy is not sufficient to fully fund needed educational services, it enables school districts to continue to contract with the centers at substantially less cost than serving severely retarded children directly in the public schools.

The state also eliminated the old method of direct funding of teachers for the moderately retarded in 1980 . With the change, districts received all of their special education funding according to the total pupil count (average daily membership) of both handicapped and nonhandicapped students. This money could be used by the local districts to serve any handicapped or gifted children. Unlike the old system of separate funding for teachers of different disability groups, the newer method provided no incentive to serve any highcost children directly in the school if a cheaper nonpublic school alternative, such as the developmental day center, existed.

The importance that attitudes play in determining how children are served is illustrated by the fact that most moderately handicapped students continue to be served directly in the public schools even though a financial incentivethe state legislative subsidy-now exists to place them in segregated developmental centers along with the severely handicapped. Since 1980 , only a handful of administrators have attempted to return moderately handicapped back to the developmental centers and take advantage of the state subsidy. This fact evidences the overwhelming acceptance that the idea of serving the moderately handicapped in public schools has achieved.

\section{B. Effect of Attitudes, Failed Leadership and Funding Patterns on Service in the Schools}

In contrast to the problem of the continued segregation of the severely retarded in nonpublic school settings, the treatment of the moderately and severely retarded students who are served directly by the public schools cannot be explained by state-level funding incentives. Attitudes based on the historic treatment of the retarded and the lack of state leadership in changing these attitudes have played major roles in continuing segregated placements for many of these students. These factors, as well as funding patterns, have

34. Interview with Jim Barden, Coordinator for Federal Title VI.B. State Plan, N.C. Dep't of Public Instruction, by Karen Sindelar (Oct. 31, 1984). The subsidy for fiscal year 1979-80 was $\$ 1,674,743$. Interview with Henry Thomas, Director of Budget Development and Administration, N.C. Dep't of Public Instruction, by Karen Sindelar (Jan. 11, 1985). 
combined to continue a system of inferior services for retarded students inside and outside segregated settings. Categorical special education funds have been insufficient to provide retarded students with services such as music and physical education which are normally provided from general funds for the education of all children, and special educators have been unable to gain access to general funds for these purposes. This section explores the attitudinal, leadership, and funding factors that have contributed to the continuing phenomena of segregated and inferior services for retarded students served directly in the public schools.

When the public schools in North Carolina began serving the moderately retarded in the 1950's, the segregated institutional service model was the norm. Administrators and educators knew little about educating the moderately retarded. These students were devalued, and were considered to be in need of protection and to be capable of only extremely limited progress. Placement in separate schools or in separate areas of regular schools that served elementary age students reflected the retarded students' devalued status and offered them the protection they were perceived to need. Parents supported this protective attitude toward their children as strongly as service providers did.

The model of segregated service and placement in age-inappropriate settings was continued as larger numbers of moderately retarded students entered the schools in the 1960's and 1970's. With larger numbers of students, many districts moved toward placing all their retarded students in separate schools. The schools chosen were often those determined to be no longer adequate for nonhandicapped students because of age or poor physical facilities; not surprisingly, some buildings were schools that had been used by black students during times of racial segregation. Despite their physical inferiority, the organizational separateness of these schools offered advantages. Having a principal and staff totally committed to serving retarded children helped foster feelings of institutional pride and loyalty among staff and parents. These feelings were, of course, even more pronounced in a few districts where totally new facilities for the retarded were built.

Attitudes also explain why, prior to the passage of the EAHCA, retarded students who were placed in regular schools received unequal services and facilities. As noted above, these students were generally placed in basements or separate wings in schools for much younger children, ostensibly for their own protection. The age differences between the retarded students and the rest of the students in these schools and the physical isolation of their classrooms made the retarded students the "stepchildren" of their schools. Often, they were not considered for programming in all the "extras"-music, art, and physical education-as regular students were. When they were considered, their devalued status often led principals to conclude that they could not benefit from these services. Vocational education was uncommon, as elementary schools lacked both the required personnel and facilities. Some communities, however, were large enough to support a "sheltered workshop," 
offering vocational training to handicapped adults. In the communities with workshops, older retarded students were sometimes bussed away from school for part-day placement in the workshop.

The passage of the EAHCA in 1975 and of the comparable North Carolina state law, the Creech Bill, in 1977, ${ }^{35}$ did not bring about dramatic changes in any of these areas. Although there were many causes for this, three in particular were noticeable: lack of leadership at the state level, absence of parent advocacy, and lack of leadership at the local level.

In North Carolina the division within the State Department of Public Instruction that implements federal and state special education laws is the Division for Exceptional Children. In the decade since the EAHCA was first passed, the Division has generally maintained a passive posture concerning implementation of the Act. The Division did not initially support the Creech Bill. Similarly, the Division's leadership in controversial areas has been nonexistent. Instead, the Division's philosophy has been similar to that of the State Department as a whole, that is, to leave all decisions to local districts unless assistance is requested and, when rendering assistance, to refrain from establishing general guidelines applicable to all local districts. This approach, though certainly consonant with the American philosophy of local control over education, as well as with the political realities circumscribing the State Department's role in education, has not provided the leadership for major changes in local attitudes that were needed for successful implementation of a difficult law. Thus, although experience from the 1950's through the mid1970 's had shown that placement in segregated and age-inappropriate settings and the lack of adequate services and vocational education were problems that the moderately retarded faced statewide, there was no systematic attempt to address those issues on the state level. Instead, the State Department's efforts consisted of educating administrators about the procedural requirements of the EAHCA and regulations, and of providing consultants to assist local administrators and teachers in choosing curricula and special materials for the retarded.

The State Department was not alone in its failure to push for change. The one statewide advocacy group for the retarded, the Association for Retarded Citizens (ARC), neither raised the issues of segregation, age-inappropriate placement, and lack of services with the State Department nor attempted to focus the attention of local affiliates on these problems. Of course, the ARC's efforts were thinly spread and fragmented. As the primary voice for retarded persons and their parents and guardians, the ARC was concerned not only with education for children but also with institutional conditions, strengthening of sheltered workshops that trained adults for employment, establishment of group homes, and creation of day services for retarded adults in local communities. Voluntary citizen organizations are capable of only limited success without paid professional staff, and the staff of the state ARC consisted of

35. Creech Bill, 1977 N.C. Sess. Laws 927 (codified as amended at N.C. GEN. STAT. §§ $115 \mathrm{C}$ -106 to $-115,-139$ to $-145(1983))$. 
only two people. It is not surprising that, as a local ARC director stated, "We hoped and thought the law would do it for us."36 Certainly the visible changes that occurred immediately after passage of the law-service to all retarded children and free bus transportation, which parents had generally had to provide themselves in prior years-were evidence that the EAHCA was making changes in key problem areas. The fact that retarded children were still not receiving comparable services or vocational training was not a pressing concern as long as the children were taken to school and kept there for an entire school day. With regard to placement, only a few parents had had exposure to information and training on "normalization," so most parents continued to support placement of their children in safe elementary schools and segregated centers.

At the local level, the special education directors were the persons most capable of improving services for retarded children. They had control of the funds made available by the state and federal governments for educating the handicapped. They also had been trained by the State Department concerning the Act's requirements, and had continuing contact with the State Department. However, these administrators were not familiar with "normalization" in education, so they provided little leadership in integrating retarded students. In the area of services, although they almost uniformly agreed that offering comparable services and facilities to the handicapped was desirable, they had neither the authority nor the funds to do so.

Few special education directors supported integration of the retarded into regular schools in age-appropriate settings. Drawn from the ranks of local school personnel, most had neither been trained in normalization principles nor seen them in practice. Many of these administrators had played instrumental roles as teachers or principals in the segregated schools established by local districts prior to the legal changes in the mid-1970's. They were advocates for children, but they had no reason to think that placing children in regular schools would improve their education. So with little leadership from the State Department, the directors generally continued the practices that had existed in their systems until the mid-1970's. Where segregated schools existed, they continued. Where they had never existed, retarded students continued to be housed in separate parts of schools serving younger students.

Administrators were more uniformly supportive of the need to upgrade facilities and services for the retarded, but limited funding and authority hindered their ability to make needed changes. The special education directors did have direct control over segregated schools, if their districts had such schools. Their budgets were not large enough, however, to justify using special education funds to finance major physical improvements in these inferior facilities. Moreover, superintendents and local school boards, with a few exceptions, usually had no desire to use local funds to improve facilities for

36. Interview with Jim Pritchard, Executive Director of the High Point Association for Retarded Citizens, by Karen Sindelar (June 7, 1984) (on file with the N.C. Governor's Advocacy Council for Persons with Disabilities). 
the retarded. With regard to services such as physical education, music, and art, these activities were supposed to be funded through regular education dollars, given for the benefit of all students. Most of the segregated schools were small, serving thirty to eighty children, and did not have enough students to justify teachers in these areas from the regular education budget. The activities were thus unavailable because financing them out of special education dollars could not be justified when so many more basic needs, such as teacher aides, speech therapy, physical therapy, and occupational therapy, still had to be met.

The special education directors were also severely limited in their ability to improve services for students placed in regular schools. Unfortunately, passage of the EAHCA changed little in the politics or division of responsibilities in local school systems. Principals generally control such things as placement of classes in their schools and scheduling of classes for art, music, and physical education. Special education administrators control only the hiring of teachers for the handicapped and provision of related services from the special education funds which they directly administer. Since special education funding was insufficient to hire separate art, music, and physical education teachers for the retarded, the attitude of the principal generally determined the availability of these services for handicapped students served in integrated settings.

\section{Vocational Education and the Retarded}

Both fiscal and attitudinal factors explain the continued lack of vocational opportunities for the retarded. Vocational education developed as a separate field long before the EAHCA. Vocational education is expensive, partly because of the need for vocational facilities and equipment for hands-on training, and partly because of the small teacher-pupil ratio needed for handson instruction. New special education funds were sufficient to cover only basic services (such as teachers) for handicapped students. If retarded students were to receive vocational education, a substantial part of the financing would have to come from regular vocational education dollars. Fortunately, the federal government mandated that 10 percent of federal vocational education funds be used for handicapped students, ${ }^{37}$ and required that a certain amount of state and local funds be spent as "matching" money. Overall, however, state and local funding made available for handicapped vocational education was miniscule, amounting to only 2 percent of the total state and local funds being spent for vocational education. ${ }^{38}$ It was easy to ignore the retarded in this area, as most were placed in facilities where vocational educa-

37. 20 U.S.C. $\$ 2310$ (a) (1982).

38. Vocational Education Data System Study, supra note 25. The statistics show that between 1978 and 1980, the federal government used approximately 8 percent of federal vocational education funds for handicapped education. However, state and local funds financed over 90 percent of vocational education and only 2 percent of these funds were used for the handicapped. Other observers have actually reported a decline in state and local support for handicapped vocational education. See Ognibene, Preparing Individuals with Special Needs for Work-Related Placement in Cooperation 
tion was not normally offered, such as elementary schools or older segregated facilities.

Shifting service arrangements caused by the passage of the EAHCA also caused a decline in vocational education for retarded students. Prior to 1975, many retarded students aged 16 and older were given vocational training free of charge in local sheltered workshops. After the EAHCA was passed, most workshops requested contract money from school districts for services which were previously free. Most school districts refused and, as a result, many retarded students received no vocational training.

The State Department's vocational education curriculum presented additional barriers to retarded students who were placed at the junior high and high school level where vocational education was a normal offering. The curriculum was and is organized around a sequence of courses starting with general introductory courses that require substantial academic skills in reading and math. Retarded students cannot pass the introductory courses and therefore cannot gain entry to the hands-on training available only in advanced courses. In addition, vocational instructors generally had no experience working with handicapped students, and special educators had no experience in hands-on vocational education. These institutional barriers, illustrating again the failure of regular education to accommodate special education, demanded sustained and creative leadership from state and local special education directors to resolve. Unfortunately, such leadership was lacking at both the state and local levels.

In sum, attitudes based on historical practice, the failure of state leadership, and significant funding incentives have contributed to the maintenance of an entirely segregated nonpublic school system for the severely and profoundly retarded. Similar factors, with the exception of funding incentives, explain why moderately retarded students served directly by schools are often placed in segregated settings. Attitudes, the allocation of power within local districts, and the inadequacy of the special education budget to finance courses that should be financed from regular education funds and vocational funds explain the continued discrimination against the retarded in the provision of enrichment services and vocational training.

\section{IV}

\section{Analysis of Successful Change}

It is instructive to examine how integrated educational programs which do provide comparable services, age-appropriate settings, or strong vocational programs came to be established. Although a single factor is rarely responsible for creating institutional change, a particular factor will often act as an impetus and set into motion other forces that in combination produce change. Some of the motivating factors that have had an impact on improving services

with Business and Industry, in Interchange: Office of Career Development for Special PopulaTrons (College of Educ., Univ. of Ill., Jan. 1984). 
for the retarded are examined in this section. In addition, the parameters and limitations of each of these agents of change are analyzed.

\section{A. Financial Factors}

Financial and pragmatic considerations have been strong enough in a few school districts to overcome longstanding attitudes about services to the moderately retarded. This effect is illustrated by the development of age-appropriate programs in a number of rural, relatively "backward" school districts. In a limited survey conducted in North Carolina in 1982, eight school districts in the state had developed age-appropriate high school programs for older retarded youth. ${ }^{39}$ Most were large rural county districts not considered particularly progressive in their educational practices. The reason given by most of these districts for having developed their programs was the centralized location of the high school. Most of the districts had relatively small populations of older retarded students. Their most centralized schools were high schools; their elementary and middle schools were smaller and more scattered. It was more economical to serve older retarded students in one centralized high school than to serve them in scattered smaller groups.

Of course, in at least as many cases, financial and pragmatic considerations favor the maintenance of the status quo. Overall, however, it seems that financial factors neither significantly hinder nor promote change. For example, regarding the maintenance of segregated schools, the number of students in these facilities is usually not so large that they cannot be physically accommodated in regular schools. In many school districts individual school attendance boundaries are changed and students shifted from one attendance area to another with regularity, thus moving retarded students into regular schools would not present unusual administrative problems. Also, segregated facilities in many cases are old and in need of repair; the cost of transferring students is considerably less than the cost of extensive renovations. Similarly, there is no clear financial advantage in maintaining retarded students who are placed in regular schools in age-inappropriate settings or denying them comparable services. It costs no more to serve a child in an age-appropriate setting than in an age-inappropriate one. The savings gained from denying music, art, and physical education to retarded students are insignificant. In most cases, the students' needs could be taken care of through scheduling changes and a slight reallocation of existing teachers' times rather than through hiring additional teachers. Providing vocational education could present more of a problem as it is already perceived as a scarce resource for nonhandicapped students. However, at least some services from the regular education budget could be extended without great financial sacrifice.

Financial considerations may be a more critical factor with regard to transferring the severely retarded out of nonpublic placements and into the public schools. The legislative subsidy for children placed in the segregated devel-

39. N.C. Report on Age-Appropriate High School Programs, supra note 16. 
opmental day centers is large-presently over $\$ 4,000$ per year per child.40 This incentive has been strong enough to motivate a few school districts to attempt to place their moderately retarded students back into the developmental centers. It is certainly an important enough factor to discourage districts from considering new ways to serve the severely retarded that could result in considerable financial loss.

Since financial considerations in most cases have not been the deciding factor in determining the location and extent of service for the moderately retarded, the roles that various persons in the bureaucracy have played in establishing progressive programs must also be examined.

\section{B. Leadership by Local Special Education Directors}

Local special education directors, or their equivalents, possess the greatest ability to promote systemic change in a school district. Although as a general rule no systemic change comes without approval of the superintendent, local education directors are in the best position to educate superintendents and enlist their support for changes. Limitations on the powers of a local director have already been partially explored. In North Carolina, the budgets they control are not large enough to cover all handicapped children's needs without funding some services from the general education budget. In addition, local special education directors have no direct control over school principals. The degree to which these factors limit the power of the director depends on the model of organization and control used in a district and the effectiveness of the local director.

Some school districts are operated on a model of centralized, hierarchical control. Where it exists, substantial changes may be relatively easy to accomplish when the real decisionmaker concerning programs for handicapped children-either the superintendent or the local director-is convinced that such changes should occur. Agreement from principals is not as important as it is under other organizational forms. Thus, one district relocated six classes of moderately retarded students of all ages to different schools between one school year and the next because central directors had become convinced of the educational advantages of age-appropriate education. Not surprisingly, the district was an urban district with a well-organized and powerful central bureaucracy. Pupil reassignments were also a regular occurrence because of the previous consolidation of two systems, a continuing effort to maintain certain racial proportions, and development of "magnet" schools.

In contrast, principals in most districts wield greater power and frequent reassignment of students is less common. In these districts, transferring students from one school to another may require the assent of various princi-

40. The amount given to school districts for each child placed in a developmental day center for school year $1984-85$ is $\$ 4,015$ plus over $\$ 200$ in federal money. This compares with $\$ 3,027$ available from all sources if the child is served directly by a school district. Interview with Carolyn Perry, Consultant, Division of Exceptional Children, N.C. Dep't of Public Instruction, by Karen Sindelar (Jan. 11, 1985). 
pals, which demands greater political skill from the special education administration. Whatever the degree of centralized control in a district, the availability of enrichment courses and vocational education will most often depend on the principal since, as previously discussed, the special education budget is not large enough to fund these services separately for handicapped students.

Skilled special education administrators can have substantial influence over principals. In some districts, extensive services are uniformly offered to the retarded because principals have been cultivated and educated by special education administrators. Unfortunately, such leadership is the exception rather than the rule. The author has observed situations in which retarded students have been "dumped" into regular schools with no advance preparation or education of the principals by special education administrators. In one school, for example, relatively high-functioning moderately retarded students ate lunch separately from nonhandicapped students and received no physical education for an entire year because the principal, one of the most agreeable in the system, had been told by another principal that the students would be hurt by physical activity and contact with other students. The situation, which easily could have been prevented by the special education director, was rectified by a few interested parents.

In sum, although local special education directors generally do not directly control either placement of classes for the retarded or the extent to which they receive certain services, they can exert considerable influence over these issues through leadership. School districts in North Carolina that have the most integrated and extensive system of services for the retarded generally have directors who are effective leaders. Such directors keep abreast of developments in special education practices. They are "political," demonstrating an understanding of key administrators and of the internal allocation of power in their district, as well as an understanding of how to work with and sometimes manipulate parent groups. They are generally personable, persuasive, and energetic with a desire and ability to influence others.

\section{Establishment of Programs by Individual Teachers}

Strong advocacy by individual teachers with training or experience in highquality programs has provided another avenue for change. Such teachers have independently convinced individual principals to give retarded students full access to enrichment services and have created successful hands-on vocational education programs by persuading and educating regular vocational teachers to work with handicapped children. The most successful and integrated high school program for moderately retarded students in North Carolina was created through the efforts of one teacher. ${ }^{41}$

41. Handicapped Succeeding in High School, ACCEPT: The Newsletter of the Advoc. Center for Children's Educ. and Parent Training, Aug. 1984, at 5. The program, located in Moore County, a mixed urban-rural school district, serves 22 moderately retarded students. The program is in a high school of 1,500 students. In addition to receiving special instructional services normally 
Teachers, however, are more limited as agents of change than local directors. A teacher is forced to work with the principal of the school where he or she is located, unlike local directors who may exercise some choice in determining where to locate a new or controversial program. A teacher advocating educational reform may find it difficult to alter the position of a principal who has a negative attitude toward such reform. In addition, neither the interests nor authority of a teacher are likely to extend beyond his or her own program. If a successful program is replicated or expanded, it is generally because of the interest and leadership of the special education director. It is not uncommon, therefore, to find a well-integrated program with a full array of enrichment courses for moderately retarded students in one school, while a similar program in a nearby school languishes in the basement without extra services. This unevenness in program quality occurs frequently in districts where the local directors cannot replicate successful programs either because of their own attitudes or limited skills, or those of the superintendent.

\section{Parents and Change}

Parents, individually or in groups, may also be effective in motivating change. In one North Carolina district, an individual parent organized a parent group to successfully block the transfer to a segregated developmental center of moderately retarded children who for many years had been served directly by the schools. In another district, the local ARC successfully pressured the district to more completely integrate retarded children into a regular school from the isolated wing where they had been served. Its success in that district prompted the ARC to examine educational offerings to retarded children in all schools. In another district, an individual parent educated the local director about the benefits of normalization; the director then moved a number of classes for moderately retarded students out of a segregated school. Countless principals in North Carolina have been educated by parents about retarded students' potential and needs. In a number of districts, parent activism has brought improvements to individual programs in the form of new equipment, more services, additional teachers, or additional local money from the school board.

The role that an energetic parent or group of parents can play in bringing about change is virtually unlimited, as shown by the examples above. Parents can educate the professional educators, in particular, principals, local directors, and superintendents. Where change is blocked by a reluctant or obstinate bureaucrat at one level, parents can exert pressure at the next level, something employees within the system often cannot do. Parents can present issues and needs to the school board, a forum which is often off-limits to a special education director who must support the superintendent's budget priorities and public stands. And parents can use the media to publicize issues of

given the moderately retarded, the students attend regular vocational classes, work part-time, participate in clubs, go to lunch, and attend assemblies and other school functions. The program is unique for the degree of integration it has achieved. 
concern, a tactic particularly effective for complaints about unequal services and one that is not available to local directors and special education teachers.

In light of the potential effectiveness of parents, it is unfortunate that there has not been more activism among parents. Much has been written about the failure of the EAHCA to bring about the effective parent involvement that was envisioned by its drafters. ${ }^{42}$ It is not within the scope of this article to examine why parents of handicapped children have not become actively involved in their children's education programs. Lack of education, lack of experience and sophistication in negotiating with professionals, bureaucratic obfuscation and hostility, and parental deference to educators explain much of this general passivity. The issue of concern in this analysis is why parents of retarded children who are actively involved in the children's education have generally failed to advocate integration to improve their education. The reasons for this failure include the same lack of exposure to models of normalization that affects service providers, the nonexistence of local advocacy groups in many communities, the lack of both leadership and a political focus in local voluntary associations, and the limitations of due process as an avenue for systemic change.

There has been no systematic effort by the State Department to educate parents concerning the benefits of normalization. Parents' main sources of information are the service providers who educate their children and who are likewise unknowledgeable about the benefits of normalization. Where children are placed in segregated programs with adequate physical facilities, parents tend to be extremely supportive of the programs and resist efforts to merge them into regular schools. Parents with children in integrated programs are similarly supportive of their programs. Parents with a perspective independent from that of the local service model generally come from three groups: newcomers in a school district who have experienced the advantages of a different model elsewhere; parents whose children have been in a preschool program administered by a different public agency or private concern; and parents who are professionals in other fields such as mental health and mental retardation. In local districts using a segregated service model, these parents cannot single-handedly reorient both service providers and other parents supportive of the system. Thus, progressive parents who support integration resort to due process or, probably more frequently, move to a different district offering superior services.

A second reason that parents are not more effective in advocating change is the difficulty of organizing groups and using them effectively when they exist. The oldest parent and advocacy organization in North Carolina is the ARC, yet only thirty-five of one hundred counties in the state have local ARC chapters. Rural counties with a poor, undereducated, and dispersed population are particularly likely to lack such groups. Those local groups that do exist are generally overextended. Only the largest local chapters have a paid

42. See Clune \& Van Pelt, A Political Method of Evaluating the EAHCA and the Several Gaps of Gap Analysis, Law \& Contemp. Probs., Winter 1985, at 7. 
staff, never consisting of more than one person, and most chapters are purely voluntary. Their concerns cover all agencies providing services-schools, sheltered workshops, mental health day programs, institutions, and group homes-as well as the frustrating gaps in the service system that the local chapters fill themselves through volunteer efforts or fundraising. The membership of these groups is often dominated by service providers who are interested in enlisting volunteers and support from parents rather than in conducting a critical examination of existing services and "old guard" parents who still remember the days when many retarded children were left totally uneducated. For these older parents, whose children are long past school age, the battles have already been fought and largely won. Their interest is now in development of community residential services so that their children can be cared for when the parents are gone. Existing ARC's, then, generally are not a strong factor in promoting educational change; they limit themselves primarily to enlisting general community support for projects which need funding. Hardnosed advocacy work comes, if at all, only in areas where services do not exist and need to be created. In the last four years, the author is aware of only a handful of ARC's that have given sustained attention to the quality and scope of local education opportunities for retarded children.

Group advocacy on education issues generally comes from new and often short-lived coalitions of parents and teachers that are sometimes loosely associated with, but rarely controlled by, an existing ARC. These groups form to deal with a particular problem and usually disband after the problem has been resolved. They are usually reactive rather than proactive. Most frequently, such groups have formed to resist a transfer from a segregated to a more integrated setting. As previously discussed, parents generally defend what they know and thus "radical" change, such as shutting down a segregated school, is usually resisted by parents and teachers who will be affected by the change. Because of the success of integrated programs and the legal preference (however weak) for placement in the least restrictive environment, it is rare for a district to attempt to resegregate retarded students once they have been integrated into the schools. However, in one case in the last four years in which such a move was attempted, parents successfully organized and resisted the change. Parents have only occasionally organized to improve existing programs through the addition of services or improvement of facilities, but where they have done so they have been uniformly successful. In part, this success comes about because these issues, unlike the segregation/integration controversy, unite parents and teachers and sometimes special education administrators. Also, when the issue of inferior facilities or inequitable services is directly raised it is difficult for administrators to defend. Such issues also have powerful media appeal.

Many parents are forced to use due process hearings to try to change the placement of the education programs that serve their retarded children. These parents choose due process hearings for a variety of reasons. Frequently, hearings are chosen because an advocacy group does not exist or 
cannot be persuaded to work for the needed changes. As noted, organized groups do not exist in many areas; where they do exist, they may resist supporting a challenge to an existing segregated school. Most parents who are unhappy with their children's education are not community organizers. They do not have the background, skills, time, or energy to organize a new group, or to educate or redirect the concerns of an existing group. In addition, legal assistance is more generally available than assistance in community organizing. Many parents have an exaggerated faith in the effectiveness of the more legalistic route of the due process hearing. At the same time, they distrust local political process and lack confidence in their ability to bring effective community pressure to bear on a problem. The due process hearing at least offers an "impartial" decisionmaker as a guarantor of some fairness in the process and result.

Unfortunately, hearings do not remedy systemic failures to implement the least restrictive environment or to offer services in age-appropriate settings. In systems that offer segregated services or age-inappropriate settings, ageappropriate alternative settings and integrated placements do not exist, and thus an individual child plaintiff cannot easily be moved to the desired setting. Hearing officers are reluctant to order remedies that would necessarily change the placement of other children. As a result, remedies for complaints concerning least restrictive environment or age-inappropriateness usually consist of ordering some slight accommodation to an existing program for children with a different disability. For example, a hearing officer may order that a moderately retarded child be moved to an existing integrated program for mildly retarded children rather than order a change in placement for a number of other moderately retarded children. Although such a remedy technically offers integration or age-appropriateness, it often does not provide an appropriate program for the individual child plaintiff.

Whether hearing officers would more readily make a decision that affects other children in cases involving lack of comparable services is a matter of conjecture. It certainly is not as invasive to order additional services for a group of similarly-situated retarded students as it is to move them to a different school. Technically; of course, the remedy would exceed a hearing officer's power, which is to provide an individual remedy for the complaining child. Interestingly, however, no due process hearings concerning inferior services for the retarded have been held in North Carolina. Few parents have become aroused over this issue. In the few cases where parents have made an issue of inferior services, improvements have been obtained prior to hearings through individual negotiation or community pressure.

\section{V}

\section{A Strategy for Change}

To speed up the integration of retarded children into the American educational mainstream and eliminate the pervasive discrimination they suffer, a multifaceted strategy must be adopted. Different strategies should be used to 
address the problems of the severely retarded and the moderately retarded. This section discusses these strategies.

\section{A. Federal Funding Incentive Program}

The barriers to changing services for the severely retarded are more imposing than those faced by the moderately retarded. Major factors in this difference are the fiscal subsidies that support a largely segregated system for the severely retarded and the institutional interests committed to preserving these subsidies. As forty-nine states in this country have chosen largely segregated service models for serving their severely and profoundly retarded population, ${ }^{43}$ it seems probable that funding patterns favoring continued segregation exist all over the country. ${ }^{44}$ The lack of existing successful alternatives to segregated schools also militates against changes in the existing system. The possibility of amending federal law or regulations so as to absolutely prohibit segregated schools is politically unfeasible in the near future given the nearly unanimous resistance that would come from all states and from many parents. It seems, then, that the most feasible and effective method of starting to bring about change in this area would be a federal incentive program in which funds would be provided to states interested in desegregating their service system.

Precedent for such an effort exists in the Emergency School Aid Act which, prior to its termination, funded the transistion of school districts toward greater racial integration. ${ }^{45}$ Although funding transitional efforts in all states would be ideal, the necessity of restricting costs would mandate a more limited effort. Since services for the severely and profoundly retarded are uniformly segregated throughout the United States and a strong catalyst for change is needed, at least two-thirds of the grants made available should go to states interested in desegregating services for this population; the remaining one-third should go to states which maintain segregated services for the moderately retarded on a state-wide level. Receiving states should be funded for a period of three years, primarily to effect a transition. As a condition for receipt of funds, states should have to assure that state funding for services to the retarded which was previously directed toward segregated centers would "follow the child" after integration. This would help ensure that services are not drastically reduced once integration is achieved. In states in which more than one agency funds segregated day services for the retarded, both agencies should have to maintain their funding during and after the transition.

Financing a change in even a small number of states would illustrate the feasibility of the integrated service model for severely and profoundly

43. See supra note 14 .

44. For example, in Roncker v. Walter, 700 F.2d 1058 (6th Cir. 1983), cert. denied, 104 S. Ct, 196 (1983), funding patterns favoring continued segregated school placement for the moderately retarded in Ohio were described. Moderately retarded students in the special state schools received state funding not available to districts serving the retarded locally. Id. at 1060-61.

45. Emergency School Aid Act, 20 U.S.C. $\$ \S 1601-1619$ (1976), repealed by Education Amendments of 1978, P.L. No. 95-561, §617(10)(b)(2), 92 Stat. 2268. 
retarded students. Of course, promoting the integration of the severely retarded into regular school districts will not ensure that quality programs are established. To encourage the creation of adequate programs, the federal govenment should increase support for model programs which demonstrate significant quality and in which there is an intentional, planned approach toward integration of the handicapped with nonhandicapped.

Even with implementation of federal funding as suggested above, progress toward integration of the severely handicapped will probably be extremely slow. It is also questionable whether further integration of the severely and moderately retarded is desirable, given that the retarded who are presently in regular public school settings still face substantial discrimination. It seems, then, that concurrent with the federal initiative outlined above, a sustained effort should be undertaken to address the lack of equity and meaningful integration in existing public school programs for moderately retarded. A strategy to achieve progress in this area should focus primarily on the attitudinal and institutional barriers that have impeded change in the last decade in spite of the mandates of the EAHCA. In-depth leadership training for the various levels of education professionals as well as parents should be provided. These efforts should be accompanied by regulatory changes that would eliminate some of the ambiguity in present law and regulations. These suggestions are explored in greater depth below.

\section{B. Leadership Training}

Leadership training for local special education directors, principals, teachers, and parents would increase both the will and the capacity to create change at the local level. Teachers, with the support of principals, are able to create good programs in individual schools, and parent groups and special education directors are capable of creating systemic changes. Leadership training for all of these actors in the education system should be directed toward a number of goals. It should provide an education concerning the benefits of normalization and expose potential leaders to successful examples of integrated, age-appropriate programs in which retarded students receive a full array of services normally offered to the nonhandicapped. It should also provide skill training to enable these potential leaders to identify barriers to change, to persuade others concerning the benefits of change and to identify resources, such as persons outside of the bureaucracy, to provide support and help meet needs. Finally, the training should provide a mechanism by which key actors within each local system are brought together in a parent-professional partnership to support each other and maximize chances of success. In addition, training should provide professionals with new contacts from other nearby systems who can provide needed professional peer support.

Although the specifics of such a training program cannot be detailed in this paper, some guidelines can be offered. First, it appears that, at a minimum, four persons from every district should receive training-the local special education director, a principal, a teacher, and a parent. Although the 
selection of the administrator would be automatic, the selection of an appropriate principal, teacher, and parent would not be. The principal should be chosen by the local administrator, as the principals in a school district who have shown an interest in handicapped children's needs are easily identified by local directors. The teachers and parents should be chosen by local teacher groups and, where they exist, by parent groups so as to give these organizations knowledge about the goals of the training and an investment in its outcome. The identity of the trainers is also critical. In order to ensure the most generalized support for the program as well as broad perspective, the training group should include a state educational consultant, a local administrator, and a parent advocate from a recognized advocacy group, such as a federally funded parent training project, the State Protection and Advocacy System, or the state ARC.

A program that would target one-third of a state's school districts per year and provide at least two years of follow-up training for each school district would not be expensive. Based on parent training that has been done in North Carolina, an estimate of the cost in this state would be approximately $\$ 200,000$ per year. ${ }^{46}$ Providing a similar training program nationwide would cost less than $\$ 10$ million per year, a relatively small sum when measured against the federal funds currently distributed under the EAHCA, an amount in excess of one billion dollars per year. ${ }^{47}$

The dual assumptions underlying the proposed training model are that educating different actors creates more possibilities for change, and that leadership can be strengthened, if not created. It is doubtful that a training program will have an immediate systemic impact in local districts in which the special education director has no leadership or administrative potential or has a strong personal bias against an integrated, normalized service model. Nonetheless, the training received by the other local actors in these districts could result in new pressures to force the director to take action, or to force a superintendent to bypass a passive or hostile director. In addition, even if systemic changes in such districts do not occur, changes in individual school programs may. In districts in which the local director is sympathetic to the desired change but has not previously been effective, the training will offer new allies at the local level, needed skill training, and peer support from outside the district. Involvement of the State Department of Public Instruc-

46. See Division of Personnel Preparation and Training, Final Report of the Parents' EduCational Advocacy Center (PEAC) 1981-83, Division of Personnel Preparation and Training (Oct. 17, 1983) (grant \# G008101539) (on file with the U.S. Department of Education and the N.C. Governor's Advocacy Council for Persons with Disabilities, Raleigh, N.C.). The PEAC project was one of numerous parent training projects funded by the U.S. Department of Education, and cost approximately $\$ 200,000$ over a two-year period $(\$ 120,000$ the first year and $\$ 80,000$ the second year). Among other things, the project gave intensive two-day training to a cadre of 62 parents of exceptional children statewide to function as trainers and technical assistants to other parents in the area of the EAHCA, and gave shorter training (six hours) to 746 parents and professionals in local workshops. It is estimated that approximately 200 administrators, parents, teachers, and principals could be given intensive two or three day training per year with the same amount of funds.

47. See Appropriations Act, 1985, Pub. L. No. 98-619, 98 Stat. 3324 (1984). 
tion and a statewide advocacy group may also create or strengthen pressures from outside to create change locally, as well as generate publicity and awareness of changes that occur in other local districts.

Of course, it is probable that the leadership potential or interest of the various trainees in some districts will be so low that no change will occur either on a systemic or individual school level. Training programs never guarantee uniform results. The proposed program merely recognizes the importance of an area that has previously been ignored by the federal government, that of educating and reinforcing the actors at the local level who are instrumental in creating change.

\section{State Monitoring and the Need for Federal Pressure}

The potential for vigorous state monitoring of segregated and inadequate services for the retarded already exists under the Act. The EAHCA and its implementing regulations require states to evaluate the effectiveness of programs provided the handicapped, ${ }^{48}$ mandate state and local reporting of statistics concerning the different placements in which handicapped children are served, ${ }^{\mathbf{4 9}}$ and require that the state agency ensure that local districts place children in the least restrictive environment. ${ }^{50}$ The regulations also authorize the states to use funds for training, personnel development, and public information and sharing of successful program models. ${ }^{51}$ It is clear, then, that under current law states could, if they desired, drastically reduce segregated placements through strict monitoring and positive training of the type already described. Also, under their general monitoring authority states could collect information on age-appropriate placements, comparability of services, and provision of vocational education.

The failure of North Carolina and other states to monitor implementation of the least restrictive environment requirement and to collect information on other identified problem areas is, as discussed before, a reflection of the historic relationship between the state and local districts. The passive approach is politically safe. The state's failure to modify this approach can largely be attributed to the lack of strong federal pressure and leadership. For example, federal representatives conducting periodic monitoring visits to North Carolina have observed systems in which totally segregated facilities were the only available placement for moderately retarded students, and heard complaints from statewide advocacy groups concerning the state's failure to enforce use of the least restrictive environment. There has been no federal response to these issues in the past. Federal failure to monitor state enforcement of least restrictive environment has been amply documented by numerous national

48. 20 U.S.C. $\S 1413(\mathrm{a})(11)(1982) ; 34$ C.F.R. $\S 300.146$ (1984)

49. 20 U.S.C. $\$ 1418$ (b)(2) (1982); 34 C.F.R. $\$ 300.227$ (1984).

50. 20 U.S.C. $\S 1412(5)$ (B) (1982); 34 C.F.R. $\$ 330.550$ (1984) (state agency must ensure local compliance with least restrictive environment (LRE)); id. $\S 300.555$ (state must give technical assistance on LRE); id. $\$ 300.556$ (state agency must monitor LRE and take corrective action where there is noncompliance)

51. 34 C.F.R. $\S \S 300.370$, .380-.387, 330.555 . 
advocacy groups. ${ }^{52}$ Given the passive attitude of the federal government, there has been no incentive for North Carolina and other states to adopt a more aggressive posture and upset an established relationship between state and local authorities. Clearly, then, there is a need for a more aggressive federal approach to stimulate a more aggressive state approach.

How the state would respond to stronger federal pressure is a matter of conjecture. North Carolina has readily monitored local compliance with clear federal mandates, such as the procedural requirements of the EAHCA. It is probable that the state would also monitor compliance with the least restrictive environment mandate and the provision of comparable services and vocational education if the federal regulations in these areas were less ambiguous, or if strong federal policy statements concerning existing regulations were issued and made a part of the federal government's periodic monitoring of the states. Without a more aggressive federal posture, however, it seems certain that monitoring and leadership from state agencies in the area of least restrictive environment will remain weak.

\section{The Federal Role: Clearly Articulating the Legal Requirements}

The United States Department of Education could ensure greater integration of and equity in educational programs for retarded children by strengthening federal regulations or, at the least, by issuing policy statements defining existing regulations. The Department would also have to monitor these requirements in its periodic federal visits to state agencies. It does not seem necessary to rewrite the statutory language of either the EAHCA or section 504 of the Rehabilitation Act of $1973^{53}$ in order to strengthen the administration of these acts. Although neither law specifically proscribes segregation or the failure to offer comparable services, both laws are broad enough to support regulatory language which adequately addresses these issues.

The current regulations implementing the EAHCA which address the requirement that handicapped students be educated in the least restrictive environment contain subjective language allowing significant professional dis-

52. See, e.g., Report by the Education Advocates Coalition on Federal Compliance Activities to Implement the Education for All Handicapped Children Act (P.L. 94-142), 4-23 \& app. 4 (Apr. 16, 1980) (unpublished manuscript) (on file with the N.C. Governor's Advocacy Council for Persons with Disabilities). The Coalition is a nationwide coalition of advocacy groups including state-based advocacy groups working in eleven different states and national groups such as the Children's Defense Fund, Mental Health Law Project, and National Center for Youth Law. In its report, the culmination of six months of investigation, the coalition determined that ten critical areas were being ignored by states and by the Department of Education in its monitoring activities. Continued unnecessary segregation was one of the ten problem areas. Other issues included lack of services for institutionalized children, illegal suspension and expulsion of handicapped children, and denial of necessary related services. The coalition report documents that the Department of Education has (1) consistently relied on state assurances of compliance with the least restrictive environment mandate, (2) failed to collect needed data from the states, and (3) failed to analyze data that has been provided. The Department has also consistently failed to take action when advocates shared data concerning least restrictive environment violations. In some of these cases, law suits eventually had to be filed to correct problems previously brought to the attention of the federal government. See id. at app. 4.

53. 20 U.S.C. $\$ 794$ (1982). 
cretion, thereby making it easy to continue whatever service arrangements happen to exist in a district. One regulation does nothing more than repeat the vague statutory language of the EAHCA mandating contact with the nonhandicapped "to the maximum extent appropriate". 54 Similar qualifying language is utilized in the regulation concerning the provision of nonacademic services. ${ }^{55}$ The directive that districts offer a "continuum" of services" appears to ensure that every handicapped student have available an array of services options; however, there is no mandate that the required continuum be offered for each individual disability category. As a result, some systems which routinely segregate their severely and profoundly retarded, or even moderately retarded, students by placement in segregated schools claim to fulfill the continuum requirement by offering special classes for more mildly retarded students in regular schools. In fact, these special classes are not useful or appropriate for the more substantially handicapped who may realistically have only one service option-the segregated school.

The regulation which sets forth considerations to be used in placing a child under the EAHCA ${ }^{57}$ is also easy to circumvent. Although there is a preference for placement in the child's home school, a district can easily structure a child's individualized education program to show a need for placement in a different school by including services not available in the home school. One subsection, stating that districts may consider the harmful effect of a less restrictive placement on the child or on the quality of services available, seems to be a license for districts to routinely continue placing children in segregated settings with concentrated services. ${ }^{58}$

Regulations promulgated under section 504 of the Rehabilitation Act are scarcely clearer. Both the general provisions and those specifically for preschool, elementary, and secondary education discourage separate services, but allow them where necessary to provide the handicapped student with effective services, or where the student cannot be "satisfactorily" educated in the regular education environment even with the use of supplementary aids or services. ${ }^{59}$ The regulations also clearly recognize the existence of separate facilities for the handicapped. ${ }^{60}$ Under these regulations, recipients who wish to concentrate special educators and related services personnel in one facility may do so in reliance on the argument that they are only able to offer effective services in this setting.

54. 34 C.F.R. $\$ 300.550$ (1984) (emphasis added). Compare 20 U.S.C. $\$ 1412(5)$ (B) (1982).

55. 34 C.F.R. $\$ 300.553$ (1984). The regulation provides that the handicapped shall participate with the nonhandicapped in nonacademic and extra curricular services such as meals, recess, counseling, athletics, transportation, health services, recreational activities, clubs, and employment assistance "to the maximum extent appropriate." See also id. $\$ 300.306$.

56. Id. $\$ 300.551$. The continuum includes regular classes, resource rooms, special classes, special schools, home instruction, instruction in hospitals and institutions, and itinerant instruction.

57. Id. $\$ 300.552$ (1984). Placement should be determined annually, be based on the child's IEP, be as close to the child's home as possible, and be in the child's home school unless the IEP "requires some other arrangement."

58. Id. § $300.552(\mathrm{~d})$.

59. Id. $\$ \S 104.4$ (b)(1)(iv), (b)(2)(b), (b)(3), 104.34(a), (b), 104.37(c).

60. Id. $\S 104.4(\mathrm{~b})(3), 104.34(\mathrm{a}),(\mathrm{c})$. 
On the other hand, section 504 regulations are clear in their requirement that the disabled be offered both facilities and services that are equal and comparable to those provided the nonhandicapped.61 Surprisingly, the EAHCA regulations are less clear. They guarantee that handicapped students receive a "variety" of program options ${ }^{62}$ and that physical education be made "available."63 However, they do not guarantee that services be equivalent in amount. An equivalence requirement should be added to the EAHCA regulations to provide a more clear-cut mandate. This is especially important since the Supreme Court held in Smith v. Robinson that claims covered by the EAHCA must be brought under that statute rather than under section $504 .^{64}$

It does not seem possible, however, to end segregated schooling entirely through regulation. Segregated schooling is recognized in the EAHCA; its elimination would contradict congressional intent. There is also considerable disagreement concerning the advantages of segregated schooling for particular subgroups such as the deaf and the severely and profoundly retarded. The political resistance to any such move would probably be considerable and prevent any dramatic change.

A more realizable goal would be to make more modest changes that can be used by proponents of reform as they challenge local practices or uniformly segregated state systems. One possibility would be to require every local district to make a regular school placement available to every handicapped student who requests it, with provision in the regular setting of all instructional, related, and support services offered to similar students in a segregated setting. Essentially, this would require every system that segregates the more substantially handicapped to create and fund a dual system of services upon parents' request. The expense of supporting a dual system would be an incentive for districts to move towards a fully integrated service model. In addition, parents wishing to avail themselves of less restrictive placements could avoid the current necessity of due process hearings since their right to a less restrictive alternative would be absolute. ${ }^{65}$ Although such an amendment would undoubtedly be resisted by administrators, it would be less controversial among parents, advocacy groups, and educators than other alternatives since it would not prohibit segregation, but would assure the availability of more placement options.

61. 34 C.F.R. $\$ 104.4$ (b)(ii)-(iii) (services for handicapped must be equal to those provided nonhandicapped and as effective); id. $\$ 104.34(\mathrm{c})$ (services and activities in separate facilities must be comparable to those provided the nonhandicapped).

62. Id. $\$ 300.305$ ("Each public agency shall take steps to insure that its handicapped children have available to them the variety of educational programs and services available to nonhandicapped children . . . including art, music, industrial arts, consumer and homemaking education, and vocational education."); id. $\$ 300.306$ (guaranteeing handicapped children an "equal opportunity" to participate in nonacademic and extracurricular activities).

63. Id. $\S 300.307$ (a) ("physical education services, specially designed if necessary, must be made available to every handicapped child receiving a free appropriate public education.") (emphasis added).

64. Smith v. Robinson, 104 S. Ct. 3457, 3473-74 \& n.22 (1984) (where $\$ 504$ and the EAHCA are the same or similar in substantive requirements, plaintiff must pursue claim under the EAHCA).

65. Cf. 34 C.F.R. $\S 300.550$ (b)(2) (1984). 
Regulatory revisions will result in little change unless there is a concerted effort at the federal level to enforce these regulations through federal monitoring of the states. Fortunately, in 1984 there were some indications that the federal government is interested in enforcing the least restrictive environment requirement after years of virtually total passivity. ${ }^{66}$ Whether the new federal rhetoric will be followed up in its compliance visits to the states will probably determine whether federal attention to this area has an impact.

The strategy for change outlined above will be most effective if action occurs on all fronts. Leadership training at the local level clearly will have little impact if state fiscal policies continue subsidization of statewide segregated schools for the moderately and severely retarded. And desegregation through a federal incentive program or stricter federal and state monitoring could be harmful rather than helpful to the retarded if the will and capacity of leaders at the local level to provide good integrated programs is not increased. Regulatory change will have little impact alone unless accompanied by stronger monitoring. Clearer regulations could also help attorneys and advocates for the retarded in challenging segregated systems or integrated systems offering inferior and unequal services. Such challenges, however, have been infrequent in the last five years because of continuing controversies over the advantages of segregation and integration and the high cost of undertaking major class action litigation. Given the Supreme Court's ruling in Smith $v$. Robinson, ${ }^{67}$ denying attorney fees in EAHCA cases, major systemic challenges will be even rarer. Certainly they cannot be relied on to fulfill the federal and state governments' enforcement roles in this area.

\section{VI}

\section{ConCLUSION}

Using North Carolina as an example the author has explored why services to moderately, severely, and profoundly retarded students remain inadequate and unduly segregated despite the guarantees of the EAHCA and section 504 of the Rehabilitation Act. Public attitudes toward the retarded, established service arrangements, and lack of leadership from state and local administrators and advocacy groups have contributed to the lack of change. In addition, for the severely and profoundly retarded population, fiscal subsidies established by the state legislature in response to lobbying by institutional interests have created disincentives for the development of integrated services. Legal remedies are not adequate to force change.

A coordinated approach in which a sustained program of leadership training at the local level is accompanied by clearer legal definition and stronger monitoring of the least restrictive environment and comparability of services requirements is needed. Such efforts should especially be directed

66. Will, supra note 8. Interestingly, Mrs. Will in this speech strongly critized states for not enforcing least restrictive environment, but did not recognize the total absence of federal enforcement in this area that has existed in the past.

67. 104 S. Ct. 3457 (1984) (attorney fees not available for EAHCA claims). 
toward the moderately handicapped as there is presently greater promise for improvement in services to this group. In addition, for states in which a statewide segregated system of services for either the moderately or severely and profoundly retarded exists, a new federal desegregation incentive grant program is proposed. The author also recommends regulatory changes that would strengthen requirements that the handicapped receive services equivalent to those received by the nonhandicapped and would give parents an absolute right to services in a regular school if desired. In the author's opinion, the proposed changes are all politically feasible and are not unduly expensive, especially compared to total federal funding under the EAHCA. Without a new multi-pronged approach to the specific problems retarded students continue to face, progress toward both integration and equality of services will be spotty and halting and will proceed no faster than it has in the past decade. 